\title{
Causation of Borrmann type 4 gastric cancer: heritable factors or environmental factors?
}

\author{
Ying Liu ${ }^{1}$, Kimio Yoshimura ${ }^{1}$, Naohito Yamaguchi ${ }^{1}$, Kazuya Shinmura ${ }^{2}$, Jun Yokota ${ }^{2}$, and Hitoshi Katai ${ }^{3}$ \\ ${ }^{1}$ Cancer Information and Epidemiology Division, Research Institute, National Cancer Center, Tokyo 104-0045, Japan \\ ${ }^{2}$ Biology Division, Research Institute, National Cancer Center, Tokyo, Japan \\ ${ }^{3}$ National Cancer Center Hospital, Tokyo, Japan
}

\begin{abstract}
Background. The prognosis of Borrmann type 4 gastric cancer remains poor today. The relative contributions of genetic factors and nongenetic factors to type 4 gastric cancer are unclear. The study of family history and spousal history of cancer may play an important role in the assessment of causation of this severe gastric cancer.

Methods. During the period 1995-1997, 1118 consecutive patients with histologically confirmed gastric cancer (probands), including 113 with type 4 carcinoma, were admitted to the National Cancer Center Hospital. The type of carcinoma, as well as the family history of cancer in first-degree relatives and spouses of the probands, was abstracted from medical records. Family history and spousal history of cancer were compared between type 4 and other types of gastric cancer.

Results. While paternal history had no association with type 4 carcinoma compared with other types, maternal history was associated with a fourfold risk $[95 \%$ confidence interval (CI), 1.6-9.3] of daughters' type 4 carcinoma, but not sons'. Among probands whose wives had a history of gastric cancer, the risks of type 4 gastric cancer were significantly increased, to as high as 13-fold (95\% CI, 2.5-65.3). However, husbands' history had no relationship with wives' type 4 carcinoma. No relationship between type 4 carcinoma and family history or spousal history of other cancers was observed.

Conclusion. The present study suggested that environmental factors may have a key effect in causing type 4 carcinoma. The findings may be valuable for identifying subjects at high risk of such malignant gastric cancer as Borrmann type 4.
\end{abstract}

Key words Borrmann type 4 carcinoma - Family history · Spousal history $\cdot$ Environmental factors

Offprint requests to: $\mathrm{Y}$. Liu

Received: June 3, 2002 / Accepted: September 19, 2002

\section{Introduction}

Despite a decline in its incidence, gastric cancer remains a major cause of death in Japan and worldwide [1]. It is estimated that there were over 1 million new cases diagnosed yearly worldwide [2], accounting for nearly $10 \%$ of all new cancers. Advanced gastric cancer is classified into four Borrmann types, 1 to 4, with a supposedly increasing degree of malignancy [3]. About $10 \%$ of gastric cancers are of Borrmann type 4, which is a relatively undifferentiated carcinoma with little or no glandforming capability. Despite recent advances in the diagnosis and medical treatment of gastric cancer, most tumors of type 4 are not detected at an early stage and the prognosis remains poor. The 5-year survival rate after gastric resection ranges from 0 to $17 \%$ for type 4 , compared with $35 \%-70 \%$ percent for other types of carcinomas $[1,4,5]$.

A high incidence of gastric cancer in close relatives of affected individuals [6-11] has suggested that genetic factors as well as environmental factors are important for the pathogenesis of gastric cancer. However, the relative contributions of genetic and environmental factors are poorly understood $[12,13]$, and whether more severe gastric cancers such as type 4 carcinomas are more heritable than milder types is not yet reported.

On the other hand, although married couples usually have different genetic backgrounds, they share home environments and lifestyle for years, with a possible mutual effect on dietary habits, smoking, alcohol intake, and sexual practice. Several studies have observed concordances in precancerous gastric lesions or gastric cancer in married couples [14-16]. Correspondence in the occurrence of cancers in spouses may give us information on the magnitude of the influence of environmental factors.

Although the relative contributions of genetic and nongenetic factors to type 4 carcinoma are of great concern among physicians, there is no previous report on 
this issue available. To our knowledge, this is the first study that has aimed to clarify environmental factors and heritable factors contributing to type 4 gastric cancer by examining the family history of first-degree relatives who share $50 \%$ of the gene and home environment with the affected individuals (probands) and the history of spouses, who share the home environment only with the probands.

\section{Subjects and methods}

\section{Probands}

The probands were patients with histologically confirmed gastric cancers who were admitted to the National Cancer Center Hospital of Japan during the years from 1995 to 1997. The nurses in charge interviewed them in detail to make a medical record when they were admitted to the hospital. Past histories of cancer in relatives up to the third-degree and in spouses were necessarily included. Surgical and endoscopic or pathological reports on the type of gastric cancer or on its histological pattern were also included in the medical records. The records for all patients were reviewed by one of the authors.

Histological type was determined by the predominant malignant cell types according to the Japanese classification of gastric carcinoma [17]. Intestinal- or diffuse-type of cancer was classified by using the criteria of Lauren [18]. The macroscopic type of Borrmann type 4 carcinoma is defined as diffusely infiltrated carcinoma in which ulceration is usually not a marked feature [17].

Among a total of 1126 consecutive patients, 5 foreigners and 2 patients with incomplete information on family history were excluded. We further excluded a patient with a family history that met the Amsterdam criteria of hereditary nonpolyposis colorectal cancer. Finally, 1118 probands remained in the analysis. In order to minimize information bias, we limited the past history of cancer to first-degree relatives and spouses only, as their histories were likely to have been reported with greater accuracy compared with those of more distant relatives $[19,20]$.

\section{Statistical analysis}

Logistic regression analysis was used to obtain odds ratios for type 4 gastric cancer in relation to family history and spousal history of cancer; $95 \%$ confidence intervals were calculated by using standard errors of the logistic regression coefficients. Because age of onset is related to the size of a pedigree and the occurrence of gastric cancer, we adjusted age of onset as a continuous variable. All computations were performed by using the SAS software package version 8.2 (SAS Institute, Cary, NC, USA).

\section{Results}

About 10\% (113/1118) of carcinomas were diagnosed as type 4 , and with the percentages in male and female probands being $8 \%(62 / 783)$ and $15 \%(51 / 335)$, respectively.

Table 1 shows the age distribution and histological pattern of the probands. Female probands were younger than males, and both males and females with type 4 gastric cancer were younger than those with other types. Although there were many more males than females with gastric cancer on the whole, female patients outnumbered males at age 39 and below. Type 4 carcinoma tended to be more frequent than other types among male patients in their thirties and forties,

Table 1. Background information of probands with Borrmann type 4 and other types of gastric cancers

\begin{tabular}{|c|c|c|c|c|}
\hline \multirow[b]{2}{*}{ Variable } & \multicolumn{2}{|c|}{ Male } & \multicolumn{2}{|c|}{ Female } \\
\hline & Other types $(n=721)$ & Type $4(n=62)$ & Other types $(n=284)$ & Type $4(n=51)$ \\
\hline Mean age (years) ${ }^{\mathrm{a}}$ & $61.3(0.4)$ & $57.8(1.5)$ & $59.2(0.8)$ & $57.6(1.8)$ \\
\hline \multicolumn{5}{|l|}{ Age (years) } \\
\hline$\leq 29$ & $5(0.7)$ & $1(1.6)$ & $4(1.4)$ & $1(2.0)$ \\
\hline $30-39$ & $16(2.2)$ & $5(8.1)$ & $21(7.4)$ & $3(5.9)$ \\
\hline $40-49$ & $83(11.5)$ & $9(14.5)$ & $45(15.8)$ & $11(21.6)$ \\
\hline $50-59$ & $200(27.7)$ & $18(29.0)$ & $58(20.4)$ & $14(27.5)$ \\
\hline $60-69$ & $250(34.7)$ & $19(30.7)$ & 87 (30.6) & $8(15.7)$ \\
\hline$\geq 70$ & $167(23.2)$ & $10(16.1)$ & $69(24.3)$ & $14(27.5)$ \\
\hline \multicolumn{5}{|l|}{ Histological pattern } \\
\hline Intestinal type & $433(60.2)$ & $8(12.9)$ & $113(39.9)$ & $3(5.9)$ \\
\hline Diffuse type & $283(39.4)$ & $54(87.1)$ & $168(59.4)$ & $48(94.1)$ \\
\hline Other & $3(0.4)$ & 0 & $2(0.7)$ & 0 \\
\hline
\end{tabular}

Values in parentheses are percentages unless otherwise specified

a Values in parentheses for mean age are standard errors of the mean 
Table 2. Odds ratios (OR) and $95 \%$ confidence intervals (CI) of Borrmann type 4 gastric cancer (GC) according to family history of gastric cancer

\begin{tabular}{|c|c|c|c|c|}
\hline & \multicolumn{2}{|c|}{ No. of probands } & \multirow{2}{*}{$\begin{array}{c}\text { Crude OR } \\
(95 \% \text { CI })\end{array}$} & \multirow{2}{*}{$\begin{array}{l}\text { Age-adjusted OR } \\
(95 \% \mathrm{CI})\end{array}$} \\
\hline & Other types & Type 4 & & \\
\hline \multicolumn{5}{|c|}{ Probands overall } \\
\hline \multicolumn{5}{|c|}{ Family history of GC } \\
\hline Negative & 784 & 80 & 1.0 (Referent) & 1.0 (Referent) \\
\hline Positive & & & $1.5(1.0-2.3)$ & $1.6(1.0-2.4)$ \\
\hline 1 & 175 & 25 & $1.4(0.9-2.3)$ & $1.5(0.9-2.4)$ \\
\hline$\geq 2$ & 46 & 8 & $1.7(0.8-3.7)$ & $2.0(0.9-4.3)$ \\
\hline \multicolumn{5}{|c|}{ Male probands } \\
\hline \multicolumn{5}{|c|}{ Family history of GC } \\
\hline Negative & 569 & 46 & 1.0 (Referent) & 1.0 (Referent) \\
\hline Positive & & & $1.3(0.7-2.4)$ & $1.4(0.8-2.6)$ \\
\hline 1 & 121 & 12 & $1.2(0.6-2.4)$ & $1.3(0.7-2.6)$ \\
\hline$\geq 2$ & 31 & 4 & $1.6(0.5-4.7)$ & $1.7(0.6-5.2)$ \\
\hline \multicolumn{5}{|c|}{ Female probands } \\
\hline \multicolumn{5}{|c|}{ Family history of GC } \\
\hline Negative & 215 & 34 & 1.0 (Referent) & 1.0 (Referent) \\
\hline Positive & & & $1.6(0.8-3.0)$ & $1.6(0.9-3.1)$ \\
\hline 1 & 54 & 13 & $1.5(0.8-3.1)$ & $1.6(0.8-3.2)$ \\
\hline$\geq 2$ & 15 & 4 & $1.7(0.5-5.4)$ & $1.9(0.6-6.4)$ \\
\hline
\end{tabular}

Table 3. Odds ratios (OR) and $95 \%$ confidence intervals (CI) of Borrmann type 4 gastric cancer (GC) according to relatives with gastric cancer

\begin{tabular}{|c|c|c|c|c|}
\hline & \multicolumn{2}{|c|}{ No. of probands } & \multirow{2}{*}{$\begin{array}{c}\text { Crude OR } \\
(95 \% \text { CI })\end{array}$} & \multirow{2}{*}{$\begin{array}{l}\text { Age-adjusted OR } \\
\quad(95 \% \mathrm{CI})\end{array}$} \\
\hline & Other types & Type 4 & & \\
\hline \multicolumn{5}{|l|}{ Probands overall } \\
\hline Father with GC & 104 & 12 & $1.0(0.5-1.9)$ & $1.1(0.6-2.1)$ \\
\hline Mother with GC & 65 & 13 & $1.9(1.0-3.5)$ & $2.0(1.0-3.7)$ \\
\hline Sibling with GC & 92 & 15 & $1.5(0.8-2.7)$ & $1.7(0.9-3.0)$ \\
\hline \multicolumn{5}{|l|}{ Male probands } \\
\hline Father with GC & 73 & 6 & $1.0(0.4-2.3)$ & $1.0(0.4-2.5)$ \\
\hline Mother with GC & 50 & 4 & $0.9(0.3-2.7)$ & $0.9(0.3-2.7)$ \\
\hline Sibling with GC & 57 & 9 & $1.9(0.9-4.1)$ & $2.2(1.0-4.7)$ \\
\hline \multicolumn{5}{|l|}{ Female probands } \\
\hline Father with GC & 32 & 6 & $1.1(0.4-2.7)$ & $1.1(0.4-2.8)$ \\
\hline Mother with GC & 15 & 9 & $3.8(1.6-9.3)$ & $4.0(1.6-9.8)$ \\
\hline Sibling with GC & 34 & 6 & $1.0(0.4-2.5)$ & $1.0(0.4-2.6)$ \\
\hline
\end{tabular}

and in female patients in their forties and fifties. About $90 \%$ of type 4 carcinomas were diffuse type, and females with other types of carcinomas had a higher frequency of diffuse type than males.

The relationship between type 4 gastric cancer and family history of gastric cancer is summarized in Table 2. The odds ratio of having type 4 gastric cancer compared with other types was significantly increased among probands with a family history of gastric cancer. Although statistically nonsignificant, higher odds ratios were observed the more family members were affected. A similar result remained when the probands were divided into a male group and a female group.
Table 3 gives the details of family history and risk of type 4 gastric cancer. Overall, patients with a maternal history of gastric cancer had a statistically significantly elevated risk of type 4 carcinoma. However, such a relationship existed only in female probands and their mothers, but not in male probands. As for male probands, an increased age-adjusted odds ratio for type 4 carcinoma was noted when they had siblings affected with gastric cancer. Paternal history showed no impact on the risk of type 4 carcinoma.

No excess odds ratios for type 4 were observed where there was a family history of other cancers (Table 4). 
Table 4. Odds ratios (OR) and $95 \%$ confidence intervals (CI) of Borrmann type 4 gastric cancer according to family history of cancers other than gastric cancer

\begin{tabular}{|c|c|c|c|c|}
\hline & \multicolumn{2}{|c|}{ No. of probands } & \multirow[b]{2}{*}{ Crude OR (95\% CI) } & \multirow[b]{2}{*}{ Age-adjusted OR $(95 \% \mathrm{CI}$} \\
\hline & Other types & Type 4 & & \\
\hline \multicolumn{5}{|c|}{ Probands overall } \\
\hline \multicolumn{5}{|c|}{ Family history of other cancers } \\
\hline Negative & 675 & 79 & 1.0 (Referent) & 1.0 (Referent) \\
\hline Positive & & & $0.9(0.6-1.3)$ & $0.9(0.6-1.4)$ \\
\hline 1 & 256 & 28 & $0.9(0.6-1.5)$ & $0.9(0.6-1.5)$ \\
\hline$\geq 2$ & 74 & 6 & $0.7(0.3-1.6)$ & $0.8(0.3-1.8)$ \\
\hline \multicolumn{5}{|c|}{ Male probands } \\
\hline \multicolumn{5}{|c|}{ Family history of other cancers } \\
\hline Negative & 492 & 45 & 1.0 (Referent) & 1.0 (Referent) \\
\hline Positive & & & $0.8(0.5-1.3)$ & $0.9(0.6-1.4)$ \\
\hline 1 & 181 & 14 & $0.8(0.5-1.6)$ & $0.9(0.5-1.6)$ \\
\hline$\geq 2$ & 48 & 3 & $0.7(0.2-2.3)$ & $0.8(0.2-2.7)$ \\
\hline \multicolumn{5}{|c|}{ Female probands } \\
\hline \multicolumn{5}{|c|}{ Family history of other cancers } \\
\hline Negative & 183 & 34 & 1.0 (Referent) & 1.0 (Referent) \\
\hline Positive & & & $0.9(0.5-1.4)$ & $0.9(0.5-1.4)$ \\
\hline 1 & 75 & 14 & $1.0(0.5-2.0)$ & $1.0(0.5-1.9)$ \\
\hline$\geq 2$ & 26 & 3 & $0.6(0.2-2.1)$ & $0.7(0.2-2.2)$ \\
\hline
\end{tabular}

Table 5. Odds ratios (OR) and $95 \%$ confidence intervals (CI) of Borrmann type 4 gastric cancers according to cancer status of spouses

\begin{tabular}{|c|c|c|c|c|}
\hline & \multicolumn{2}{|c|}{ No. of probands } & \multirow{2}{*}{$\begin{array}{c}\text { Crude OR } \\
(95 \% \text { CI })\end{array}$} & \multirow{2}{*}{$\begin{array}{l}\text { Age-adjusted OR } \\
(95 \% \mathrm{CI})\end{array}$} \\
\hline & Other types & Type 4 & & \\
\hline \multicolumn{5}{|c|}{ Spouses with cancers } \\
\hline All kinds & 37 & 8 & $2.2(1.0-4.8)$ & $2.5(1.1-5.7)$ \\
\hline Gastric cancer & 8 & 4 & $4.9(1.5-16.7)$ & $6.0(1.7-20.8)$ \\
\hline Other cancers & 29 & 4 & $1.3(0.5-3.9)$ & $1.5(0.5-4.4)$ \\
\hline \multicolumn{5}{|c|}{ Wives with cancers } \\
\hline All kinds & 21 & 5 & $3.1(1.1-8.6)$ & $3.9(1.4-11.1)$ \\
\hline Gastric cancer & 3 & 3 & $12.9(2.5-65.3)$ & $19.6(3.6-105.4)$ \\
\hline Other cancers & 18 & 2 & $1.4(0.3-6.1)$ & $1.6(0.4-7.2)$ \\
\hline \multicolumn{5}{|c|}{ Husbands with cancers } \\
\hline All kinds & 16 & 3 & $1.2(0.3-4.1)$ & $1.2(0.3-4.3)$ \\
\hline Gastric cancer & 5 & 1 & $1.2(0.1-10.8)$ & $1.2(0.1-10.9)$ \\
\hline Other cancers & 11 & 2 & $1.1(0.2-5.2)$ & $1.1(0.2-5.3)$ \\
\hline
\end{tabular}

The data for 60 probands without marriage history or with incomplete information on marriage status were deleted

Table 5 indicates the odds ratios for type 4 gastric cancer according to the cancer status of spouses. Risks of type 4 gastric cancer were significantly increased among probands whose spouses had a history of cancers. However, with regard to the histories of gastric cancer and other cancers, respectively, the former showed a significantly elevated odds ratio, while the latter indicated little change from unity. Among probands whose wives had a history of gastric cancer, the risks of type 4 carcinoma were remarkably increased, to as high as 12.9. On the other hand, husbands' histories had no relationship to wives' type 4 carcinoma. Adjustment for age made the risk even higher.

\section{Discussion}

A positive family history is regarded as one of the risk factors for gastric cancer and is considered to increase the risk by about two times when compared with the risk of a negative family history [6-11]. However, no previous study that investigated the relationship between family history and the severity of gastric cancer was reported. The present study found that a family history of gastric cancer was progressively positively related to type 4 carcinoma compared with other types. Even though no distinction was made between the genetic and nongenetic factors (environmental or infec- 
tious) shared by family members to explain the positive relationship of family history and type 4 carcinoma, the findings of the present study may help us to differentiate the effects of the two factors indirectly. Given that there is no difference in the genetic influence of the father and mother on their children, the lower risk for type 4 carcinoma in children with a paternal history of gastric cancer, together with a lower risk for sons with a maternal history found in the study suggests that the positive relationship between family history and risk of type 4 gastric cancer is hard to explain in terms of heritable factors. A large-scale twin study in Europe has indicated that genetic factors make a minor contribution to susceptibility to most types of neoplasms, including gastric cancer, and that environmental factors play a principal role [21]. Furthermore, studies that examined genetic factors have noted that the well-discussed DNA mismatch repair, $p 53$, and E-cadherin genes do not significantly contribute to family clustering of gastric cancer $[13,22]$. The present study revealed that there may be no more genetic influence for type 4 gastric cancer than for other types of gastric cancer.

A previous Japanese study had reported a sixfold excess risk of gastric cancer for females with a maternal history of gastric cancer [23], and the present study found a fourfold risk of type 4 carcinoma versus other types of carcinomas for females with a maternal history. The most reasonable explanation for the high risk of gastric cancer, especially of type 4 carcinoma, in the female patients with a maternal history of gastric cancer may lie in the intimate relationship between mother and daughter, which leads to similar lifestyles, with daughters being likely to keep the lifestyles learned from their mothers lifelong, while sons' lifestyles, especially dietary habits, are changed after marriage. The importance of dietary factors and other lifestyle factors in the occurrence of gastric cancer is already well documented by previous studies on immigration which showed a remarkable decline in the incidence and mortality of gastric cancer among Japanese immigrants to Hawaii [24-26], and many other epidemiological studies have also demonstrated the importance of dietary factors [27-30]. Furthermore, a Japanese study that systematically compared chronological trends in the intake of several foods/nutriments and the time trends for ageadjusted death rates of stomach cancer noted that marked changes in dietary factors during the period 1960 to 1985 have contributed to the decrease in the death rate of stomach cancer [31]. Long term accumulation of carcinogens derived from the everyday diet may be more apparent in families with a maternal history of gastric cancer than in those without, and, thus, this could have led to such severe gastric cancer as type 4 in females with a maternal history. However, there is a possibility, even though it is a slight one that cannot be eliminated completely, that genetic factors which determine susceptibility to type 4 carcinoma may be related to female sex hormonal circumstances. A previous study noted that the development and growth of gastric cancer in young women might be influenced by their natural, biological, and hormonal circumstances [32]. Another study summarized that female sex hormones or their analogues play a suppressive role in carcinogenesis or the progression of stomach cancer, and noted that pregnancy and delivery may accelerate the growth of stomach cancer [33]. Therefore, even though it seems unlikely, daughters with mothers affected by gastric cancer may be more susceptible to type 4 carcinoma.

Males and females are considered to give equally reliable responses regarding their spouses' cancer history [19]. Therefore, the unexpected findings about spousal history in the present study should not be attributed to recall bias. The very strong relationship between wives' histories of gastric cancer and husbands' type 4 carcinoma provides a further argument for the strong effect of environmental factors, especially dietary habits; this finding further decreases the possibility of the influence of female sex hormonal circumstances on type 4 carcinoma. In Japan, women usually stay at home after marriage, and wives prepare the food in almost all households, and they also do most of the other housework. Thus, wives have a great influence on husbands' lifestyles, including their dietary habits. The mean age of our 12 probands who had affected spouses was 70 years (range, 58 to 90 years). The duration between the time the probands presented to the hospital and the onset of gastric cancer in their spouses ranged from 2 to 30 years (average, 13 years). Assuming they married at 26 [34], the average length of their marriage until the spouses of the probands presented with gastric cancer was about 30 years. An immigrant study in Hawaii showed that the effect of diet on the risk of gastric cancer occurred in early life [35], which may cast doubt on the effects of diet among married couples. However, the evidence is not sufficient to clarify whether the lower risks of gastric cancer among those who migrated to Hawaii at an early age than those in adults were due to higher susceptibility to dietary factors in childhood than in adulthood or whether they were due to the correspondingly shorter period of exposure to a Japanese diet. If the latter is true, the long-term accumulation of carcinogens shared in the home may explain the correspondence of severe gastric cancer in husbands having affected wives. However, whether a particular diet is related to type 4 carcinoma in particular or whether a longer exposure time and/or larger exposure amount are determining factors for type 4 carcinoma rather for than other types of carcinoma remains unknown. Several studies have demonstrated a correspondence between husbands and wives in cancer history, 
including gastric cancer $[15,16]$. But only the present study has elicited the difference between males and females in response to their spouses' cancer history. Such a difference may suggest possible shared risk factors in the household for married couples and unshared risk factors for working husbands outside the home.

The lack of association between the risk for type 4 carcinoma and a family history of other cancers in the present study, which is in agreement with a previous study that showed no relationship between gastric cancer and a family history of other cancers [5], implies that some risk factors may specifically contribute to type 4 gastric cancer, as well as other types of gastric cancer, but not contribute to other tumors.

Besides dietary factors, infection by the Helicobacter pylori bacterium has been identified as an important risk factor for gastric cancer, especially early-stage carcinoma [36-39]. There is evidence that $H$. pylori induces precancerous changes, such as gastric atrophy and hypochlorhydria, in first-degree relatives of gastric cancer patients significantly more frequently than in individuals without a positive family history [40,41]. Furthermore, two recent studies reported that infection with $H$. pylori combined with a positive family history appeared to be a strong independent risk factor for gastric carcinoma [42,43]. However, whether $H$. pylori is related to such advanced carcinoma as type 4 remains unclear. It is known that there is no difference in infection rates of $H$. pylori between males and females, which means that the risk of infection for males should be the same as that of females if a person has an $H$. pylori-positive spouse or mother. Thus, the differences in the acquiring of type 4 carcinoma between males and females in response to their spouses' or maternal histories of gastric cancer found in the present study are difficult to explain by the contribution of this bacterium. However, early life acquisition of $H$. pylori is associated with a higher risk of developing gastric cancer than infection by $H$. pylori in adulthood [44]; different substrains of $H$. pylori may cause different degrees of malignancy [45]; and individuals differ in their susceptibility to the bacterium [46]. Whether the bacterium is positively related to type 4 carcinoma compared with other types of carcinomas merits further study.

The present study found that family history, especially maternal history, as well as a wife's history of gastric cancer, is positively associated with Borrmann type 4 gastric cancer. Environmental factors have a critical effect in causing this type of carcinoma. Genetic effects, if they exist, must be minor. Considering the low 5 -year survival rate for type 4 gastric cancer in comparison with that for other types of gastric cancer (the 5 -year survival rate of type 4 gastric cancer during the period 1989 to 1992 at the National Cancer Center Hospital was less than $12 \%$, compared with about $70 \%$ for other types), and the small improvement in the prognosis of type 4 carcinoma observed in the past decade as well (data not shown), prevention, detection, and medical treatment at an early stage are crucial. The result of our study may be valuable for identifying subjects at high risk of such malignant gastric cancer as Borrmann type 4.

The present study stratified the risks by sex of the proband and type of relative (mother, father, or sibling) or spouse (husband or wife); inevitably, this leads to small case numbers in each analytical cell, and thus odds ratios had wide $95 \%$ confidence intervals. Therefore, the observed variation in risk might be due to the play of chance on small numbers. Further investigation with a larger sample size is needed to confirm the findings of the present study.

Acknowledgments The authors thank Dr. S. Yamamoto for providing useful advice on design. This work was supported by a Grant-in-Aid for Cancer Research and for the Second-term Comprehensive 10-Year Strategy of Cancer Control from the Ministry of Health and Welfare, and a grant from the Ministry of Education, Culture, Sports, Science, and Technology of Japan. Dr. Y. Liu is an Awardee of a Research Resident Fellowship from the Foundation for Promotion of Cancer Research, Japan.

\section{References}

1. The Editorial Board of the Cancer Statistics in Japan. Cancer Statistics in Japan 2001. Tokyo: Foundation for Promotion of Cancer Research; 2001.

2. World Cancer Research Fund in Association with American Institute for Cancer Research. Food, nutrition and prevention of cancer: a global perspective. Washington (DC): American Institute for Cancer Research; 1997.

3. Hamilton SR, Aaltonen LA, editors. World Health Organization classification of tumors. Pathology and genetics of tumor of the digestive system. Lyon: IARC Press; 2000.

4. Tanigawa N, Amaya H, Matsumura M, Lu C, Iki M. Association between tumor angiogenesis and Borrmann type 4 carcinomas of the stomach. Oncology 1998;55:461-7.

5. Takeda J, Hashimoto K, Koufuji K, Kodama I, Aoyagi K, Kakegawa T. A retrospective study of resected gastric cancers. Kurume Med J 1992;39:141-5.

6. Inoue M, Tajima K, Yanamura Y, Hamajima N, Hirose K, Kodera Y, et al. Family history and subsite of gastric cancer: data from a case-referent study in Japan. Int J Cancer 1998;76:801-5.

7. La Vecchia C, Negri E, Franceschi S, Gentile A. Family history and the risk of stomach and colorectal cancer. Cancer 1992;70: $50-5$.

8. Ogawa H, Kato I, Tonimaga S. Family history of cancer among cancer patients. Jpn J Cancer Res 1985;76:113-8.

9. Hoshino H, Hirayama T, Arimoto H, Maruyama K, Kitaoka H, Yamada T, et al. Gastric cancer risk factors: a case-control study based on medical records. Jpn J Cancer Res 1985;76:846-50.

10. Kato I, Tominaga S, Matsumoto K. A prospective study of stomach cancer among a rural Japanese population: a 6-year survey. Jpn J Cancer Res 1992;83:568-75. 
11. Yu GP, Hsieh CC. Risk factors for stomach cancer: a populationbased case-control study in Shanghai. Cancer Causes Control 1991;2:169-74.

12. Zanghieri G, Di Gregorio C, Sacchetti C, Fante R, Sassatelli R, Cannizzo G, et al. Familial occurrence of gastric cancer in the 2-year experience of a population-based registry. Cancer 1990; 66:2047-51.

13. Stone J, Bevan S, Cunningham D, Hill A, Rahman N, Peto J, et al. Low frequency of germline E-cadherin mutations in familial and nonfamilial gastric cancer. Br J Cancer 1999;79:1935-7.

14. Zhao L, Blot WJ, Liu WD, Chang YS, Zhang JS, Hu YR, et al. Familial predisposition to precancerous gastric lesions in a highrisk area of China. Cancer Epidemiol Biomarkers Prev 1994;3: 461-4.

15. Walach N, Novikov I, Milievskaya I, Goldzand G, Modan B. Cancer among spouses: review of 195 couples. Cancer 1998;82: $180-5$.

16. Kato I, Tominaga S, Suzuki T. Correspondence in cancer history between husbands and wives. Jpn J Cancer Res 1990;81:584-9.

17. Japanese Gastric Cancer Association. Japanese classification of gastric carcinoma 13th Ed. Tokyo: Kanehara; 1999.

18. Lauren $P$. The two histological main types of gastric carcinoma: diffuse and so-called intestinal-type carcinoma. An attempt at a histoclinical classification. Acta Pathol Microbiol Scand 1965;64: 31-49.

19. Herrmann N. Retrospective information from questionnaires: comparability of primary respondents and their next-of-kin. Am J Epidemiol 1985;121:937-47.

20. Tepper A, Connally LB, Haltmeier P, Smith E, Sweeney MH. Knowledge of medical history information among proxy respondents for deceased study subjects. J Clin Epidemiol 1993;46:12438.

21. Lichtenstein P, Holm NV, Verkasalo PK, Iliadou A, Kaprio J, Koskenvuo M, et al. Environmental and heritable factors in the causation of cancer. N Engl J Med 2000;343:78-85.

22. Shinmura K, Kohno T, Takahashi M, Sasaki A, Ochiai A, Guilford P, et al. Familial gastric cancer: clinicopathological characteristics, RER phenotype and germline p53 and E-cadherin mutations. Carcinogenesis 1999;20:1127-31.

23. Nagase $H$, Ogino $K$, Yoshida I, Matsuda $H$, Yoshida $M$, Nakamura H, et al. Family history-related risk of gastric cancer in Japan: a hospital-based case-control study. Jpn J Cancer Res 1996;87:1025-8.

24. Kolonel LN, Nomura AM, Hirohata T, Hankin JH, Hinds MW. Association of diet and place of birth with stomach cancer incidence in Hawaii Japanese and Caucasians. Am J Clin Nutr 1981;34:2478-85.

25. Stemmermann GN, Kolonel LN. Talc-coated rice as a risk factor for stomach cancer. Am J Clin Nutr 1978;31:2017-9.

26. Kono S, Hirohata T. Gastric cancer and life-style. Jpn J Cancer Clin 1990;36:257-67.

27. Hirohata T, Kono S. Diet/nutrition and stomach cancer in Japan. Int J Cancer Suppl 1997;10:34-6.

28. Vaughan TL, Davis S, Kristal A, Thomas DB. Obesity, alcohol, and tobacco as risk factors for cancers of the esophagus and gastric cardia: adenocarcinoma versus squamous cell carcinoma. Cancer Epidemiol Biomarkers Prev 1995;4:85-92.

29. Hansson LE, Nyren O, Bergstrom R, Wolk A, Lindgren A, Baron $\mathrm{J}$, et al. Nutrients and gastric cancer risk. A population-based case-control study in Sweden. Int J Cancer 1994;57:638-44.
30. Dorant E, van den Brandt PA, Goldbohm RA, Sturmans F. Consumption of onions and a reduced risk of stomach carcinoma. Gastroenterology 1996;110:12-20.

31. Tominaga, S. Decreasing trend of stomach cancer in Japan. Jpn J Cancer Res 1987;78:1-10.

32. Maeta M, Yanashito H, Oka A, Tsujitani S, Ikeguchi M, Laibara N. Gastric cancer in the young, with special reference to 14 pregnancy-associated cases: analysis based on 2325 consecutive cases of gastric cancer. J Surg Oncol 1995;58:191-5.

33. Furukawa H, Iwanaga T, Hiratsuka M, Fukuda I, Ishikawa O, Kabuto T, et al. Suppressive effect of sex hormones on spreading of stomach cancer. Jpn J Cancer Chemother 1989;16:36915 .

34. Health and Welfare Statistics Association. Annual Statistical Review of National Health Conditions (in Japanese). Tokyo: Health and Welfare Statistics Association; 2000.

35. Haenszel W, Kurihara M. Studies of Japanese migrants. I. Mortality from cancer and other diseases among Japanese in the United States. J Natl Cancer Inst 1968;40:43-68.

36. Uemura N, Okamoto S, Yamamoto S, Matsumura N, Yamaguchi S, Yamakido M, et al. Helicobacter pylori infection and the development of gastric cancer. N Engl J Med 2001;345:784-9.

37. Forman D, Newell DG, Fullerton F, Yarnell JW, Stacey AR, Wald N, et al. Association between infection with Helicobacter pylori and risk of gastric cancer: evidence from a prospective investigation. BMJ 1991;302:1302-5.

38. The EUROGAST Study Group. An international association between Helicobacter pylori infection and gastric cancer. Lancet 1993;341:1359-62.

39. Fukuda H, Saito D, Hayashi S, Hisai H, Ono H, Yoshida S, et al. Helicobacter pylori infection, serum pepsinogen level and gastric cancer: a case-control study in Japan. Jpn J Cancer Res 1995;86: 64-71.

40. Meining AG, Bayerdorffer E, Stolte M. Helicobacter pylori gastritis of the gastric cancer phenotype in relatives of gastric carcinoma patients. Eur J Gastroenterol Hepatol 1999;11:717-20.

41. El-Omar EM, Oien K, Murray LS, El-Nujumi A, Wirz A, Gillen $\mathrm{D}$, et al. Increased prevalence of precancerous changes in relatives of gastric cancer patients: critical role of $H$. pylori. Gastroenterology 2000;118:22-30.

42. Brenner H, Bode G, Boeing H. Helicobacter pylori infection among offspring of patients with stomach cancer. Gastroenterology 2000;118:31-5.

43. Brenner H, Arndt V, Sturmer T, Stegmaier C, Ziegler H, Dhom G. Individual and joint contribution of family history and Helicobacter pylori infection to the risk of gastric carcinoma. Cancer 2000;88:274-9.

44. Blaser MJ, Chyou PH, Nomura A. Age at establishment of Helicobacter pylori infection and gastric carcinoma, gastric ulcer, and duodenal ulcer risk. Cancer Res 1995;55:562-5.

45. Chow WH, Blaser MJ, Blot WJ, Gammon MD, Vaughan TL, Risch HA. An inverse relation between cagA+ strains of Helicobacter pylori infection and risk of esophageal and gastric cardia adenocarcinoma. Cancer Res 1998;58:588-90.

46. Yea SS, Yang YI, Jang WH, Lee YJ, Bae HS, Paik KH. Association between TNF-alpha promoter polymorphism and Helicobacter pylori cagA subtype infection. J Clin Pathol 2001;54:7036. 